\title{
Editorial
}

J. Synchrotron Rad. (2000). 7, 115

\section{SR source to science}

\author{
S. Samar Hasnain, ${ }^{a \star}$ John R. Helliwell ${ }^{b}$ and Hiromichi Kamitsubo ${ }^{c}$ \\ ${ }^{a}$ Synchrotron Radiation Department, CLRC Daresbury Laboratory, Warrington WA4 4AD, UK, \\ ${ }^{b}$ Department of Chemistry, Manchester University, Manchester M13 9PL, UK, and \\ ' SPring-8, JASRI, Sayo-gun, Hyogo-ken 679-5198, Japan
}

This issue brings together papers from the satellite meeting of the XVIII IUCr Congress held last August. The meeting covered topics ranging from the 'source to science'. Such an ambitious theme was appropriate given the location of the meeting, where the first dedicated synchrotron radiation source was designed and built and from where the first recognition of synchrotron radiation work in the form of a Nobel prize to Sir John Walker came (Vol. 6, Part 4).

At the IUCr Congress in August 1999, the new and innovative electronic journal service, Synchrotron Radiation Online, was launched. This gives easy access to the complete text of all regular 1999 articles. The articles are available in HTML and PDF formats, and are richly hyperlinked for easy navigation within and between articles. The service also provides search mechanisms, e-mail alerting and immediate access to supplementary data. The online free access finishes its run in May, as publicized. We urge you and your libraries to sign up for access to Synchrotron Radiation Online.

The debate on the new sources, SOLEIL and DIAMOND, has continued to attract much attention from the media, politicians and scientists, both in France and the UK. A positive aspect of this public debate has been the increased awareness of the general public about synchrotron radiation. On 13 March the UK's Science Minister announced the location of the joint UK-French project, DIAMOND. Science Minister, Lord Sainsbury, said, 'The new synchrotron is a major capital investment, worth approximately $£ 200$ million, which will place British science at the forefront of global research. Our goal is to create the best possible facility for UK and French science - for both current and future users. After a careful analysis of scientific, technical, operational and financial issues and the views of the funding partners, we have decided that the way forward is to build the new synchrotron at the Rutherford
Appleton Laboratory near Didcot in Oxfordshire. It was a difficult decision and the Daresbury Laboratory made a good case for its location in Daresbury.' On 15 March the French Select Committee reported on the synchrotron issue. They said, 'Because of the extra cost associated with the access for users to machines abroad, a share in AngloFrench, German or Swiss machines can only be a supplementary investment in certain fields, such as biology, but certainly not a solution replacing a national synchrotron source. In order to maintain competence in synchrotron technology in France at the highest international level, and to provide thousands of French users with free, close and affordable access to the state-of-the-art methods of analysis that synchrotron radiation can offer, the construction of a machine of $2.75 \mathrm{GeV}$ should be started without further delay and in a region of easy access and with a proven scientific background.' On 27 March the French Science Minister Allegre lost the seat in the Cabinet and RogerGerard Schwartzenberg became the Science Minister. In the UK, both houses of parliament were involved in an extensive debate on the synchrotron issue on 29 March. Whatever the final outcome of this debate, we hope that the two communities can recover from the current position and ensure that synchrotron radiation thrives in the two countries in the coming decades.

We are pleased to announce that, this August, the journal will welcome Dr Dennis Mills, from the APS, USA, as one of the Main Editors in succession to Professor John Helliwell who completes seven years in office as a JSR Main Editor (1994 through to 2000). The geographical spread of the Main Editors will then specifically include North America, and is a vital next step in the growth and development of JSR. Professor Helliwell will continue to serve as Chairman of the IUCr's Commission on Journals and Editor-in-Chief of Acta Crystallographica. 